\title{
INVESTIGATING THE IMPACT OF ENTREPRENEURSHIP AND EDUCATION ON ECONOMIC GROWTH
}

\author{
${ }^{* 1}$ Badri, A. K. and Badri, P. K.
}

\author{
*1 Department of Economics, Faculty of Management and Accounting, Qazvin Branch, Islamic Azad University, Qazvin, Iran \\ Phone: +98-9148059607 Email: arashkbadri@gmail.com \\ University College of Daneshvaran \\ Phone: +98-9149027253 Email: parsabadri@hotmail.com
}

\begin{abstract}
Developments and rapid changes in the international community, moving from traditional society to the information society, as well as changing the national economy to the global economy, require different solutions to enable economic growth and development in society. In fact, entrepreneurship, which is the concept of the discovery and exploitation of opportunities for value creation in the various sectors, is the basis for an all-round development. For this reason, to develop the countries pay special attention to the entrepreneurship is very important. So, this study is trying to investigate the effects of entrepreneurship and education on economic growth in 25 selected countries using the panel-data method in the period of 2001 to 2015. The results show that entrepreneurship and education have positive effects on economic growth, so that by increasing one percent of each variable, respectively, economic growth will increase by 0.41 and 0.21 percent.
\end{abstract}

Keywords: economic growth, education, entrepreneurship, human capital, panel data

LICENSE: This work by Open Journals Nigeria is licensed and published under the Creative Commons Attribution License 4.0 International License, which permits unrestricted use, distribution, and reproduction in any medium, provided this article is duly cited.

COPYRIGHT: The Author(s) completely retain the copyright of this published article.

OPEN ACCESS: The Author(s) approves that this article remains permanently online in the open access (OA) mode.

QA: This Article is published in line with "COPE (Committee on Publication Ethics) and PIE (Publication Integrity \& Ethics)". 


\section{INTRODUCTION}

In today's world, the country which provides ideal situation for its entrepreneurs and decent infrastructures for creation of new creative ideas, can make progress in economic growth and development. The experience of developed countries shows that in all these countries entrepreneurs and entrepreneurship have had a vital role in their economic development. While also the unsuccessfulness of many developing countries is not paying enough attention to creation of new ideas and entrepreneurial activities (Shahbazi et al., 2014)

Entrepreneurs result in motivation as an important factor; this itself is the happening reason of many ideas and new thoughts in production of various products and commodities. Entrepreneurship designs the progress of beneficial activity progress and takes use of professional force in their special professions which itself is a reason of increasing efficiency in different sectors and results in improvement of economic growth and development in the society. Among the most important roles of entrepreneurship in the progress of development compilation and transfer of general non-target savings towards production, creating widespread employment, regional equal development and reducing economic focus, redistribution of wealth and income distribution becoming fairer, movement of resources, capital and unused skills in the society, increasing life quality to innovation and invention environment, increasing profit and income in the society and improvement of services given in social and cultural sectors by the governments, motivating competition, gathering and organizing resources and efficiently using them and also the factor of national evolution and revitalization are to be mentioned (Sabahi et al., 2013).

Entrepreneurship brings social profit for the society and the government and results in decent distribution of income and reduces social problems. This important subject causes technology transfer and motivates investment. Entrepreneurship results in a dynamic equality in the economy and it also can cause motivation and creation of competitiveness between various productive and economic sectors (Dhaliwal, 2016).

The process of entrepreneurship can revolutionize and revitalize of nationally and regionally. This important factor is the reason of knowing, creating and developing new markets, change and innovation and increasing productivity and creating job opportunities. Entrepreneurial activities cause improvement of life quality and it creates the right way of social life and nationalizes production and prevents pointless immigration to other regions. Entrepreneurship improves the culture of self-employment and it causes improvement of creativity culture on various social levels. This is the reason of development of cooperation in the society which results in effective and principled support for the development of the cooperative sector (Urbanoa and Aparicio, 2016).

Entrepreneurship also has the ability of making the required changes in the labor market rules in order to have more employment and cause efficient distribution of jobs in various occupied levels which results in development of self-employment culture and reduces social gaps (Ferreira et al., 2017).

For this reason, this study is trying to investigate the effects of entrepreneurship and education on economic growth in 25 selected countries of the world using the panel-data method in the period of 2001 to 2015. 


\section{THEORETICAL FOUNDATIONS}

\section{ENTREPRENEURSHIP}

The word "Entrepreneurship" comes from the French word "Entreprendre" meaning commitment to work. Webster

dictionary defines entrepreneur as someone who commits to manage, organize and take the risks of an economic activity. Also there have been various definitions for this concept. Cole (1946) defines entrepreneurship as a targeted activity which contains series of coherent decisions of an individual or a group of people in order to create development or stabilize an economic unit.

Schumpeter (1934) believed that the entrepreneur is the primary acceleration for economic development and its role is innovation. In Schumpeter's idea, the activities of entrepreneurs include offering a new commodity, offering a new method for the production progress, opening a new market, finding new sources and creating any new organization in industry, etc. He introduces the determining feature in entrepreneurship as doing new works or inventing new methods for current activities. According to Schumpeter's theory, the entrepreneur is the primary accelerator and the engine of development and its responsibility is to innovate or create new combinations of materials. He defines innovation as the primary characteristic of an entrepreneur and defines creative destruction as the job of an entrepreneur. In his book "Dynamic Economy Theory" he claims that dynamic stability comes with innovation and entrepreneurship and these are the characteristics of a healthy economy.

Cantilion (1730) defines entrepreneur as a person who provides the market with production tools in order to combine them to produce products which are distributable to the market. Lamb (1902) defines entrepreneurship as a kind of social decision making which happens by economic innovators and refers to the primary role of entrepreneurs as the application of widespread process of creating regional, national and international societies or transforming social and economic symbols. In Draker's idea (1985), entrepreneurship is a behavior; therefore, using management concepts and technics, standardization of the product and building the work are based on education. In his idea an entrepreneur is a person who starts a small new activity with their own investment. Kirzner (1973) believed that entrepreneurship is creating more mutual compatibility and coordination in the function of markets. Kirchhoff (1994) defines entrepreneur as someone who funds new companies in order to create and boom new jobs.

According to Baptiste Say (1803) an entrepreneur is someone who combines all production tools and provides the required raw material and pays for the wages of the workers, capital interest and field rent; and finally gets the resulting profit. Timmons (1990) claims that entrepreneurship is creating a valuable attitude out of nothing. Entrepreneurship is a progress which results in creating and achieving opportunities and following them regardless of the accessible sources. In his idea, entrepreneurship includes creating and distributing values and resources between individuals, groups, organizations and the society. Redlich (1958) defines entrepreneur as someone who has characteristics of a manager, supervisor and coordinator of production activities, a planner and an innovator; and is the final decision maker of the production unit.

Hisrich (1985) has given a general definition for entrepreneur which is accepted by most of various owners and theorists of fields of economics, psychology and management. In his definition, entrepreneurship is creating something different from the past and it results in the person's satisfaction with the result, financial, psychological and social risks. 
So according to the considered definitions we can say "entrepreneurship is a process in which a new value is created, which is achieved through effort and continuous following and considering the risk conditions" (Ketabforoush, 2017).

\section{THE ROLE OF ENTREPRENEURSHIP IN THE DEVELOPMENT OF SOCIETY}

Entrepreneurship is considered to be a necessity in societies and it is considered to be an important factor in achieving success and effort. Among all these, the role of entrepreneurs is vital in the development of societies; because they provide conditions for advancement and development according to their own circumstances and characteristics. Because of characteristics such as leadership, management, innovation, limitless effort and hard work, high efficiency, creating competitiveness, high performance, funding companies and productive industries, making job opportunities and so on, entrepreneurs have an important role in economic growth and development of various countries (Stuetzer et al., 2017). Form the viewpoint of many economists and owners of various sciences, entrepreneurs are like the engine of acceleration and growth and development of the societies which can lead the society towards a dynamic economy by creating a healthy and competitive environment (Lee, 2016).

Entrepreneurs can create the most efficiency in production and services with the least resources and facilities through new and innovative and creative methods (Fritsch and Wyrwich, 2017). This means producing current commodities with the least costs and the highest quality which can create newer markets for the produced commodities (Freytag and Thurik, 2007). With their skill in detecting opportunities and moving towards developing these opportunities, entrepreneurs are referred to as true pioneers of change in economy and social evolutions (Ireland $e t$ al., 2009). New activities of entrepreneurs or restarting a business results in increasing and refining function of the workers. These activities provide decent circumstances for increasing competition in different productive sectors; making other productive sectors to increase their efficiency and create some creative jobs. Inventing new methods of production can be done like this (Van Stel, et al., 2005).

Increasing efficiency and inventions in job sections in various sectors and levels in organizations has interesting impacts on mass level of societies which can provide the required circumstances for economic development and flourishment. Also, this progress makes the consumers able to take use of various products with high quality and low price (Wiklund and Shepherd, 2003).

Where there are entrepreneurs, motivation for effort and hard work happens in societies and all individuals get positive impacts from entrepreneurs. Entrepreneurs motivate individuals to do creative and entrepreneurial things which can result in growth and flourishment of the societies. Increasing efficiency, increasing quality of the products, increasing employment, increasing the morality of working and putting effort and so on are among the positive impacts of the activities of entrepreneurs in the society (Wyrwich et al., 2016).

\section{RESEARCH BACKGROUND}

Du and O'Connor (2018) studied the relationship entrepreneurship and advancing national level economic efficiency. Thier national level results also suggest that the new product entrepreneurship and to a lesser extent improvementdriven opportunity entrepreneurship both significantly contribute to the improvement of national level efficiency. 
However, both measures would benefit from further development and it seems a higher coincidence of both is more likely to advance a nation's economic efficiency.

Murphy et al. (2018) examined the enterprise financing in the emerging economies of Ghana, Pakistan and Yemen in terms of global dynamics. e methodology used is a comparative study of the three countries involving an investigation of the economic background, financial bodies, enterprises, and funding SMEs to determine the nature of financial entrepreneurship in the three countries as emerging economies. In response to the research question it was found that financial bodies have an important influence on enterprises especially in terms of the way SMEs are funded. From the findings of the comparative study a fundamental model was developed as the main contribution to knowledge concerning the financing of SMEs in emerging economies taking into account important financial aspects, the process of entrepreneurship and the significant outputs of SME activities and growth.

Coulibaly et al. (2018) have investigated the relationship between economic globalization, entrepreneurship, and development in Brazil, Russia, India, China, and South Africa (BRICS). The results show, after utilizing both estimation techniques, the variables were all positive and statistically significant, hence confirming the hypothesis. They posit the implementation of innovation-driven policies that will promote the movement of production factors, enhance South-South financial and regional trade agreements and sustain economic development in developing nations in general and BRICS economies in particular.

Asongu and Nwachukwu (2018) examined how information and communication technology (ICT) influences openness to improve the conditions of doing business in sub-Saharan Africa in the period 2000 to 2012. They find substantial evidence that ICT complements openness to improve conditions for entrepreneurship, the effects are contingent on the dynamics of openness, ICT and entrepreneurship. Theoretical and practical policy implications are discussed.

Liu et al. (2018) studied the importance of human capital, social capital, and community trust on migrants' entrepreneurial entry with cross-sectional and panel data analyses using the 2012 and 2014 Chinese Labor-force Dynamics Survey (CLDS) data. The results show that rural migrants' entrepreneurship rates and entrepreneurial entry rates surpass both their urban resident and rural resident counterparts, indicating the active role they play in urban business landscape. While individual characteristics and social networks play similar roles in these three groups' entrepreneurial transition, rural migrants' business activities are particularly shaped by their perception of communities. Further analysis of migrant-owned businesses reveals their over-representation in main-street industries but their firm performances are on par with other businesses, suggesting their positive economic contribution in cities.

Ferreira et al. (2017) studied the effects of Schumpeterian and Kirznerian entrepreneurship on economic growth using unbalanced panel data for 43 countries in thev period 2009-2013. By estimating the econometric models, they were able to calculate the effects of these two types of entrepreneurship on economic growth in the three different types of economy. In terms of the overall model for GEM economies, neither Schumpeterian nor Kirznerian entrepreneurship return any statistically significant effects on the Global Competitiveness Index or on GDP growth. However, the Total Early-Stage Entrepreneurial Activity variable generates a positive effect on the Global Competitiveness Index. The results presented in this paper provide insights into entrepreneurship and the GEM entrepreneurial economic ecosystems. 
Hahn et al. (2017) examined the entrepreneurial education and learning at universities: exploring multilevel contingencies. A multi-level analysis on a cross-country sample of 87,918 students resulting from GUESSS ('Global University Entrepreneurial Spirit Students' Survey') strongly confirms their hypotheses, and allows them to discuss implications for researchers, educators and policy makers with respect to the nature of entrepreneurial learning, the design of entrepreneurial education programs, as well as the contextual conditions that impact entrepreneurial learning outcomes.

Bonito et al. (2017) examined the impact of entrepreneurship and economic growth on poverty, income inequality and economic development. This study used regional data to obtain sufficient number of observations, obtained from official government documents. The results suggested that economic growth plays a vital role on poverty, income inequality and economic development; entrepreneurship has impact on economic development but little or no impact on poverty and income inequality in the Philippines.

Kasseeah (2016) studied the impact of entrepreneurship on economic development using regional analysis of 125 selected countries of the world. The results indicate that economic development of the countries in the sample is affected by entrepreneurship even after controlling for regional variation. These results indicate that policy makers around the world need to put in place specific policies to promote the entrepreneurship culture among their population.

Dhaliwal (2016) in a study investigated the role of entrepreneurship in economic development. The results show that the role of entrepreneurship in economic development varies from economy to economy depending upon its material resources, industrial climate and the responsiveness of the political system to the entrepreneurial function. Path breaking offerings by entrepreneurs, in the form of new goods \& services, result in new employment, which can produce a cascading effect or virtuous circle in the economy.

Shahbazi et al. (2014) in a study examined the impact of entrepreneurship and innovation on economic growth in selected countries during the period 2001 to 2011 using the data panel method. The results of the research show that entrepreneurship has a positive and significant effect on economic growth. Therefore, in order to achieve economic growth and development, it is necessary to pay more attention to entrepreneurship and innovation.

Sabahi et al. (2013) studied the effect of entrepreneurship on economic growth in selected countries using the OLS method. The results of the model estimation showed that entrepreneurship has a positive and significant effect on economic growth.

Kazemi and Mobaraki (2012) examined the effect of entrepreneurship on Iran's economic eowth by using Bayesian measurement approach. The results show that entrepreneurship has a significant effect on economic growth along with 27 other variables. This conclusion shows that the creation of the field of entrepreneurship in the country, in addition to other factors affecting economic growth, should be given special attention.

\section{INTRODUCING DATA AND ESTIMATION MODEL DATA AND RESEARCH MODEL}

The statistical population of this study is 25 selected countries of the world including Australia, Brazil, Belgium, Canada, Chile, Colombia, Denmark, Finland, France, Germany, Iceland, Ireland, Italy, Japan, South Korea, New Zealand, Netherlands, Norway, Singapore, Slovenia, Spain, Sweden, United Kingdom, United States and Uruguay. Data analysis method is using panel data method with the help of EViews software. Time series information from 
these countries has been collected from WDI (2016), with the target period from 2001 to 2015. In the current study, the model is based on a part Shahbazi et al. (2014) and Sabahi et al. (2013) which is modified as follows:

$\mathrm{LGDPP}_{\text {it }}=\beta_{0}+\beta_{1} \mathrm{LTEA}_{\text {it }}+\beta_{2} \mathrm{LEDU}_{\text {it }}+\beta_{3} \mathrm{LAP}_{\mathrm{it}}+\beta_{4} \mathrm{HEA}_{\mathrm{it}}+\mathrm{U}_{\mathrm{i}}$

LGDPP $_{\text {it: }}$ Logarithm of gross domestic product per capita

LTEA $_{\text {it: }}$ Logarithm of total early-stage entrepreneurial activity

LEDU $_{\mathrm{it}}:$ Logarithm of human capital is achieved from the multiplication of the rate of enrollment in education at an adult literacy rate

$\mathrm{LAP}_{\mathrm{it}}$ : Logarithmic total percentage of active population to total population

LHEA $_{\mathrm{it}}$ : Logarithm of health expenditure as a percentage of GDP

\section{PANEL DATA METHOD}

The econometrical model used in this study is based on panel data method. In panel data model, the data are serial and sectional which means the data are calculated during time between the sections. According to econometrical principals, the mentioned model is estimated using the Ordinary Least Squares method (OLS) and the $\beta$ ratios are acquired. This method provides more awareness information, more variation of changeability, less collinearity between the variables and more freedom and performance rates, while the series of time have collinearity. In panel data, considering the fact that they are a combination of time and section series, the sectional dimension causes adding changeability or much variation having which we can do more reliable estimations (Ashrafzadeh and Mehrgan, 2010).

\section{ESTIMATION OF THE MODEL}

In this section, the studied model is estimated. For this purpose, first the stationary of the variables is considered and then the studied model will be determined using F Lymer and Housman tests.

\section{STUDYING THE STATIONARY OF THE VARIABLES}

One of the ways to avoid fake regression is to make sure of stationary of variables For studying the stationarity of the variables there are different tests like Levin, Lin and Chu (LLC), generalized Fisher-Dickey Fooler (ADF), PhilipsPerron (PP), etc. In this study, Levine, Lin and Chu (LLC) test has been used, which is one of the most important tests of unit root in panel data. The results of this test are in table 1 below:

Table 1: The results of the model variables using LLC test

\begin{tabular}{lll}
\hline Variables & T Statistics & Prob \\
\hline GDPP & -5.4239 & 0.0000 \\
TEA & -10.2314 & 0.0000 \\
EDU & -7.4457 & 0.0000 \\
AP & -9.3125 & 0.0000 \\
HEA & -7.2145 & 0.0000 \\
\hline
\end{tabular}


According to the results of table 1, for the group of selected developing countries in Levine, Lin and Chu (LLC) all the variables are in a stable level.

\section{ESTIMATION OF THE MODEL}

The estimation of the introduced model of the study is done using panel data method. For this purpose, it is required that the method of estimation be determined for special type of cross-sectional data. In panel data estimation method two general conditions are seen. The first type is that width from the origin is equal for all sections in which it will be pool data model. The second type is that width from the origin is different for all sections which is called panel data. For distinguishing the two mentioned types, test called F-Lymer is used. So the F-Lymer test is used to choose between pool data regression methods and fixed effects regression. And the Housman test is used to choose between the two methods fixed and random effects. The results are shown in table below:

Table 2. The results of F-Limmer and Housman tests

\begin{tabular}{lll}
\hline Test & T Statistic & Prob \\
\hline F-Lymer & 852.4125 & 0.0000 \\
Housman & 65.1736 & 0.0000 \\
\hline
\end{tabular}

Reference: Research findings

As it is clear in table 2, the results of F-Lymer and Housman tests suggest the fixed effects method as the decent estimation method. So, regression method with fixed effects will be used for model estimation. For this purpose, the results of model estimation based on panel data using fixed effects method for period of 2001 to 2015 is shown in table 3.

Table 3: Results of the estimation of model using fixed effects method

\begin{tabular}{llll}
\hline Variables & Coefficient & T statistic & Prob \\
\hline LTEA & 0.4133 & 6.7532 & 0.0000 \\
LEDU & 0.2154 & 8.4177 & 0.0000 \\
LAP & 0.1287 & 10.1241 & 0.0000 \\
LHEA & 0.0231 & 5.4725 & 0.0000 \\
$\mathrm{R}^{2}=0.7512$ & $\mathrm{R}^{2 \mathrm{bar}}=0.7402$ & & $\mathrm{DW}=1.70$ \\
\hline
\end{tabular}

Reference: Research findings

As the results show, the estimated ratio for entrepreneurial index is 0.41 which shows that by 1 percent increase (or decrease) of entrepreneurial index, economic growth increase (or decrease) by 0.41 percent. The results show that the entrepreneurial index has a positive and significant impact on the growth rate of the countries under study. By improving the indicators of entrepreneurship, we can see increasing investment, increasing profits and, consequently, increasing revenues for countries. Entrepreneurship can create new job opportunities in the labor market and provide 
an effective way to create productive and sustainable employment in countries. This important factor changes the values and creates new values and facilitates the process of growth and development of countries. Entrepreneurship provides the environment and conditions for the production of goods, products and marketing, and makes emerging products, services, methods, policies, ideas and innovative solutions to solve the problems of society. This important factor can lead to competition, the strengthening and evolution of the same domestic industries with each other and eventually improve and improve the quality of goods. In other words, entrepreneurship is an important factor for economic development, welfare and social security of the community.

The estimated ratio for education index is 0.21 which shows that by 1 percent increase (or decrease) of entrepreneurial index, economic growth increase (or decrease) by 0.21 percent. The views of classical economists on the study of economic growth and development of societies have always focused on physical capital and its determinants in economic growth and there was no place for the role of human capital and human resource education in the sustainable development of societies in their analysis. After the 1950s, qualitative changes in the workforce were introduced as the skills and expertise of investing in human resource education and gradually the concept of human capital appropriately taken into consideration for efforts to train skilled manpower and its role in the economic development of communities in economic analysis. The results of experience and studies in developed countries suggest that education is closely related to economic growth, and the lack of attention to research and development and the neglect of the impact of trained and trained personnel are one of the most important factors in the low level of economic growth in developing countries. Therefore, it can be said that special attention to the subject of education can lead to different countries in achieving their goals in different sectors of the economy and society and thus lead to economic growth and development.

The estimated ratio for active population is 0.12 . Active population is one of the most important sections of production in the process of exports improvement and economic growth and development. As it is observed, due to economic and production foundation in the studied countries which are mostly considered developing countries, active population and manpower in these countries can cause more exports development and economic growth. So it can be said that existence of active population can have positive effect on products exports and services of the studied countries. It is also to be mentioned that the more active population and employment increases in the studied countries, the amount of products and production services of different economic sectors will also increase.

The estimated ratio for health expenditure variable is 0.02 which shows that with 1 percent increase (or decrease) of the index of healthcare expenditure, exports will increase (or decrease) by 0.02 percent. Health expenditure is used as a product for both consumption and investment. From consumptive perspective, individuals are looking to have health, because in that case, the enjoy life more due to improvement of life quality. From investment perspective, the relation between time and health is so that if the health situation of an individual is good, he will have shorter illness period and will have more days to work and get more income and rest and have fun.

The estimated ratio for the studied model is 0.75 which shows that independent variables of the model have been able to explain the dependent variables well. 


\section{CONCLUSION}

The obvious feature of today's economy is the rapid change. Therefore, countries can succeed in such an economy that can adapt to these changes. If we take a look at the historical course of economic development ideas, we find that the latest ideas emphasize that industry development and advancement in the economy of society are based on changing ideas and creating innovations, and without being in the forefront of science and innovation, no country will be able to follow the development path quickly. It is natural that the most prominent tool that can bring us to this goal is entrepreneurship. In the economic system based on entrepreneurship, innovators and owners of ideas and ideas are the main capital of an enterprise and are among the main factors of sustainable development. Entrepreneurship has a close relationship with the country's social and economic development, and today is considered one of the indicators of development in developing countries. Because of the special role of entrepreneurs in the process of economic growth and development, many governments in developed countries are working to maximize opportunities and exploit research achievements, leading a number of people with entrepreneurial characteristics to entrepreneurship education and entrepreneurial activities.

This study tried to investigate the effects of entrepreneurship and education on economic growth in 25 selected countries of the world using the panel-data method in the period of 2001 to 2015. For data compilation for the studied variables, the data bank of WDI was used. The selected countries of this study includes 25 selected countries of the world including Australia, Brazil, Belgium, Canada, Chile, Colombia, Denmark, Finland, France, Germany, Iceland, Ireland, Italy, Japan, South Korea, New Zealand, Netherlands, Norway, Singapore, Slovenia, Spain, Sweden, United Kingdom, United States and Uruguay. The estimated ratio for entrepreneurial index was positive. This showed that entrepreneurial index has a positive effect on economic growth in the studied countries. The estimated ratio for the education index was positive. This showed that education index has a positive effect on economic growth in the studied countries. Also, active population and health expenditure have sa positive effect on economic growth. 


\section{REFERENCES}

Ashrafzadeh, H. and Mehrgan, N. (2010). Econometric panel data. Tehran: Tehran University Cooperative Research. Asongu, S. and Nwachukwu, J. C. (2018). Openness, ICT and entrepreneurship in sub-Saharan Africa, Information Technology People, https://doi.org/10.1108/ITP-02-2017-0033

Bonito, J.D.M., Daatos, F.J.A., Mateo, J.C.A. and Rosete, M.A.L. (2017). Do Entrepreneurship and Economic Growth Affect Poverty, Income Inequality and Economic Development? Review of Integrative Business and Economics Research, 6, 1, 33-43.

Coulibaly, S.K. Erbao, C. and Mekongcho, M. (2018). Economic globalization, entrepreneurship, and development, Technological Forecasting and Social Change, 127, 4: 271-280

Dhaliwal, A. (2016). Role of Entrepreneurship in Economic Development. International Journal of scientific research and management (IJSRM), 4, 6: 4262-4269.

Ferreira, J.J. Fayolle, A., Fernandes, C. and Raposo, M. (2017). Effects of Schumpeterian and Kirznerian entrepreneurship on economic growth: panel data evidence. Journal Entrepreneurship \& Regional Development, 29, 1-2: 27-50.

Freytag, A. and Thurik, R. (2007). Entrepreneurship and its determinants in a cross-country setting. Journal of Evolutionary Economics, 17(2): 117-131. doi:10.1007/s00191-006-0044-2.

Fritsch, M. and Wyrwich, M. (2017). The effect of entrepreneurship on economic development - An empirical analysis using regional entrepreneurship culture. Journal of Economic Geography, 17(1): 157-189.

Hahn, D., Minola, T., Van Gils, A. and Huybrechts, J. (2017). Entrepreneurial education and learning at universities: exploring multilevel contingencies. Journal Entrepreneurship \& Regional Development, 29, 9-10: 945-974.

Ireland, R. D., Covin, J. G. and Kuratko, D. F. (2009). Conceptualizing corporate entrepreneurship strategy. Entrepreneurship Theory and Practice, 33(1): 19-46. doi:10. 1111/j.1540-6520.2008. 00279.x

Kasseeah, H. (2016). Investigating the impact of entrepreneurship on economic development: a regional analysis, Journal of Small Business and Enterprise Development, 23 3: 896-916, https://doi.org/10.1108/JSBED-092015-0130

Kazemi, M. and Mobaraki, M.H. (2012). Investigating the Effect of Entrepreneurship on Iran's Economic Growth Using Bayesian Measurement Approach, Journal of Development and Entrepreneurship, 5, 3, 125-144.

Ketabforoush Badri, A. (2017). Entrepreneurship and familiarity with the business process. Tabriz: Akhtar.

Lee, Y. S. (2016). Entrepreneurship, small businesses and economic growth in cities. Journal of Economic Geography. doi:10.1093/jeg/lbw021.

Liu, C.Y., Ye, L. and Feng, B. (2018). Migrant entrepreneurship in China: entrepreneurial transition and firm performance, Small Bus Econ, 2018: 1-16. https://doi.org/10.1007/s11187-017-9979-y

Murphy, L., Anwar, K., and Thomas, C. (2018). Financial Entrepreneurship in Three Emerging Economies: A Comparative Study of Ghana, Pakistan, and Yemen, Financial Entrepreneurship for Economic Growth in Emerging Nations, 1-21. DOI: 10.4018/978-1-5225-2700-8.ch001

Sabahi, A., Naji, A.K., \& Soleimani, E. (2013). The Study of the Effect of Entrepreneurship on Economic Growth in Selected Countries. Journal of Economic Growth and Development Research, 3, 11, 9-18. 
Shahbazi, K., Hasanzadeh, A. and Jafarzadeh, B. (2014). Investigating the Effects of Entrepreneurship and Innovation on Economic Growth (Panel Data Approach). Journal of Innovation and Value-Creating, 2, 5, 43-55.

Stuetzer,M., Audretsch, D.B., Obschonka, M., Gosling, S.D., Rentfrow, P.J. and Potter, J.(2017). Entrepreneurship culture, knowledge spillovers and the growth of regions. Regional Studies, http://dx.doi.org/10.1080/00343404.2017.1294251.

Urbanoa, D. and Aparicio, S. (2016). Entrepreneurship capital types and economic growth: International evidence. Technological Forecasting and Social Change, 102, 1, 34-44, https://doi.org/10.1016/j.techfore.2015.02.018.

Van Stel, A. Carree, M. and Thurik, R. (2005). The Effect of Entrepreneurial Activity on National Economic Growth. Small Business Economics, 24(3), 311-321.

Wiklund, J. and Shepherd, D. (2003). Knowledge-based resources, entrepreneurial orien-tation, and the performance of small and medium-sized businesses. Strategic Management Journal, 24(13): 1307-1314.

Wyrwich, M., Stuetzer, M. and Sternberg, R. (2016). Entrepreneurial role models, fear of failure, and institutional approval of entrepreneurship: A tale of two regions. Small Business Economics, 46(3): 467-492. doi:10.1007/s11187-015-9695-4.

Voelker, C., Permana, A., Sachs, T. and Tiong, R. (2008) 'Political risk perception in Indonesian', Journal of Financial Management of Property and Construction, 13(1): 18-34.

Weber, C. (2010), 'Quantification of Political Risk in Energy Foresight - A Method Overview. ', Retrieved in on 10 ${ }^{\text {th }}$ August, 2015 from www.isisit.com/efonet/index.php?option=com_docman\&task=doc...gid.

Zayed, T., Amer, M. and Pan, J. (2007) 'Assessing risk and uncertainty in Chinese highway projects using AHP', International Journal of Project Management, 26(4): 408-419.

Zhuang, L., Ritchie, R. and Zhang, Q. (1998). Managing business risks in China. Long Range Planning, 31(4): 606614. 